\title{
Study on the Online Travel Information Search: A Perspective of Social Media
}

\author{
Yuanfang Qian ${ }^{*}$, Jun $\mathrm{Hu}^{2,3^{*}}$, Mu Zhang3\# \\ ${ }^{1}$ Jieyang Vocational \& Technical College, Jieyang, China \\ ${ }^{2}$ Management School, Jinan University, Guangzhou, China \\ ${ }^{3}$ Shenzhen Tourism College of Jinan University, Shenzhen, China \\ Email: qianyf1987@163.com, juneloveu@163.com, ”zhangmu@163.com
}

Received 23 July 2015; accepted 23 August 2015; published 26 August 2015

Copyright (C) 2015 by authors and Scientific Research Publishing Inc.

This work is licensed under the Creative Commons Attribution International License (CC BY). http://creativecommons.org/licenses/by/4.0/

(c) () Open Access

\begin{abstract}
Social media is playing a more and more important role in the area of online information search. However, few studies are carried out about the matter in China. In the hope of contributing to the study of this subject, the author tends to explore the role of social media in online information search. This research simulates the user's online travel information search behavior. The author uses Baidu as a search engine and adopts the way of "destination + keywords" as a search model to collect data. Content analysis and multivariate statistical analysis have been used to explore the meanings of the data. This paper finds that social media provides a variety of travel information sources for users, facilitates the restructuring of the tourism information structure and changes the dissemination pattern of the travel information. Countermeasures and suggestions are given on how to provide personalized search results for the online tourists, and how to play the advantages of social media to enhance the tourism enterprises market competitiveness in the future network era.
\end{abstract}

\section{Keywords}

Tourist, Information Search, Social Media, Social Search

\section{Introduction}

According to a survey conducted by China's online tourism industry, 97\% of the internet users rely on search engines to look for travel products or reserve services. Search engines are the most ideal source for customers to

\footnotetext{
"These authors contributed equally to this study and share first authorship.

"Corresponding author.
} 
gain travel information. Travelers rely heavily on travel information before, during and after their tours. For those users who are good at Internet, 3/5 use search engines, 3/5 use travel reservation webs, 1/4 use websites recommended by other users and $1 / 5$ visit the travel information portals ( $Y u, 2010)$.

According to a study conducted by Senecal \& Nantel (2004), the decision to purchase is influenced by online recommendations as well as comments. Information gathered from different sources influences consumers' decisions to a different level. Consumers rely on recommendations made by friends and relatives as well as online comments the most, and then get information given by a third party. Commercial information comes to the last. Online travel customers with Web2.0 focus more on personal experience delivered by travelers rather than commercial information. They prefer personalized information sources to single information sources with standard contents (Sun \& Liu, 2008). In 2008, America’s OTX survey showed that nearly half of the subjects relied on families and friends for travel tips and information, 21\% used travel books and 75\% used Internet to plan their travels.

Studies above indicate that social media, typically User Generated Content, aka UGC(User Generated Content), is now becoming a customers' preferred source for travel information and is playing a more and more important role in the area of online travel. Social media influences tourism deeper and deeper. But so far, not enough attention is paid to the transformation brought by social media to tourism in China. Few studies are conducted in this area. Data is insufficient to describe and explain the role played by social media in online travel information search. Fundamental researches are urgently needed to be conducted in this area.

\section{Literature Review}

\subsection{The Progress in Studies on Travel Information Search}

Pires, Stanton \& Rita (2006) mention that online information search not only reduces transaction cost and exceeds limits posted by time and space, more importantly, it fosters a structural transformation in the balance of power between the suppliers and consumers in the travel industry. Xiang, Wober, \& Fesenmaier (2008) suggest that search engines are becoming a powerful link, a portal to provide travel related information as well as an important making channel for resorts and travel related companies to approach and persuade potential travel customers.

The study conducted by Bettman (1979) indicates that the main purpose of information search is for consumers to reduce risks and uncertainty brought by travel decisions. Internet enhances interaction between browsers with the spreading of information. Particularly the development of search engines boosts initiative to acquire information by users. Users can search information that they need with personal preference.

Hyde (2008) finds that there are three phases in decisionmaking by travel consumers, which are extensive information search for potential traveling needs, information search for specific travel plans and information search for reservation needs. These phases are closely linked to online information search. Research conducted by Dogan \& Ken (2004) showed that the behavior of information search is influenced by an interactive system composed of elements that influence one another such as travelers previous traveling experience, familiarity to the destination, knowledge about tourism, learning ability as well as costs of search. Bhatnagar \& Ghose (2004) articulate that different types of consumers have different behaviors when it comes to online information search. The conclusion is such that different amount of time is distributed among different contents and frequencies of information search. Moreover, Jun, Vogot, \& Kelly (2007) compare online information search with offline information search as well as study the relationship between the two kinds of information search and consuming behaviors. They find that different travel products, experience and phases influence one's behaviors when it comes to information search and one's ability to make decisions when it comes to travel consumptions.

\subsection{Studies on Information Search within Social Media}

Online travelers prefer to acquire social media information. Social media is represented by websites that are composed of contents posted by users such as blogs, virtual communities, Wikipedia, social networks, cooperative markings and social document sharing websites like YouTube and Flick (Gretzel, 2006; Pan, MacLaurin, \& Crotts, 2007). These social media websites assist their users to post and share travelrelated comments, opinions, personal experience and help to provide travel service information. Meanwhile, Internet is used to convey travelers’ personal travel experience. Travelers use social media websites to describe, reconstruct and relive their 
traveling experience (Pudliner, 2007; Tussyadiah \& Fesenmaier, 2009).

Chu (2001) conducted a survey on the need of Hong Kong online users for searching for flight and travel service information. Chu put forward that online travel information searchers tend to use the Internet to acquire social media information from a trusted third party, which is more reliable than commercial marketing information. Bei, Chen, \& Richard (2004) propose that when online users search for information through the Internet, they focus more information posted by other online users or travel information posted by a third party. Xiang \& Gretzel (2010) take a step further and suggest that as a travel information source.

Social media is playing a more and more important role for online users. They point out that search engines can guide online travelers directly to social media websites. Online users are entitled to more powers by social media. Pan \& Smith (2007) present that online travelers can interact with each other through reading one another's travel blogs, consumption comments as well as travel route feedbacks. Social media posts challenges to travel operators, online marketing for travel destinations and content management, particularly to travel products that are intangible and experience oriented. Pan, Litvin, \& O’Donnell (2007) analyzed four kinds of keywords, which were used by 701 online users while they tried to search for accommodation information through Excite.com... The authors explore the trend of development for the pattern of information search so as to improve marketing strategies for search engines.

Generally speaking, the studies about social media abroad started early. Researches on online travel information search went down to the details and targeted particular problems such as the relationship between the keywords for online travel information search and travel destinations or social media preference, which are pragmatic and specific. Few studies were conducted on travel information search within social media in China. Representative of these studies focus more on a general discussion about the influence that social media has on travel decision making as well as the travel marketing value for social media. There is barely a study target on the type, distribution, information structure and function of social media in travel information search. This paper is going to carry out a fundamental data analysis in this area.

\section{Methodology}

The subjects of online information search chosen by the author is limited to travel information distributed and posted on the Internet used in mainland China, which can be searched and shared online through computer end users. The subject travel information does not include information published in paper media such as magazines, newspaper, books and journals.

As online portals, the optimization and development of search engines boost initiative for online users to acquire information. Search engines are becoming the main channel to gain social media information for potential travelers. Then, when online users look for travel information online through search engines, to what percent the search results can represent social media information is the focus point of this study.

This study mainly simulates the way online users look for information about travel destinations through search engines to acquire travel related domain data. The author applies application content analysis and multivariate statistical analysis to explore the development of social media in China.

The research design is to firstly select frequently used search engines, heated travel keywords and typical travel destinations. Then search the combination of "destination + keywords" through search engines with high user infiltration rate. Next choose the top 10 pages of the search results and acquire total amount of search results for all destinations. The following step is to is to encode all the search results and conduct data analysis. The focus of this paper is then lay out through the interpretation of the data as well as the correlations among the data.

\section{Research Design}

\subsection{Choosing Search Engines}

According to studies conducted by Bertolucci (2007), Xiang et al. (2008), to explore the role that social media played in online travel information search, most countries with English as their native language use Google as the subject search engine to analyze. After pulling its server to Hong Kong, Google's market share drop immensely. In 2012, Google's market share was only around 5\%. Considering this paper is to explore social media in mainland China, Baidu is chosen to be the subject of this study due to following reasons: 1) Travel reserva- 
tions are mostly done by comprehensive search engines. According to a survey conducted by CNNIC in June, 2011, 79.6\% (equals 396 million) netizens use search engines to acquire travel information. As many as $74.6 \%$ use comprehensive search engines to look for travel reservation information. And 11\% netizens use professional vertical search engines. 9.2\% use travel reservation websites (CNNIC is short for China Internet Network Information Center, 2011). 2) Search engines have a steady user pool. Baidu has the highest infiltration rate. According to a survey conducted by CNNIC, only a percentage as small as $4 \%$ change their prime search engines in six months. That is to say, as many as $96 \%$ of netizens do not change their prime search engines in six months, making the user pool of search engines very steady. When it comes to choosing prime search engine, $95.3 \%$ of netizens prefer Baidu as their prime search engine. In 2011, Baidu has an infiltration rate as high as $98.3 \%$. Baidu infiltrates into all kinds of communities with a percentage above 95\% (CNNIC, 2011a). 3) Baidu is China's No.1 search engine. Baidu overlaps with other search engines' users to a great deal. It covers over $90 \%$ of other search engines. In October, 2011, Baidu's network traffic took up to 78\% of that of all search engines, following by Soso which was 7.3\%. Google and Sogou were in the third tier with the network traffic of $2.6 \%$ and $2.3 \%$ respectively. It can be seen from the data that Baidu is dominating the search engine market in China (CNNIC, 2011a).

\subsection{Choosing Keywords for Travel Information}

In order to study the relationship among various kinds of search engines, specific search keywords and travel destinations, keywords with the highest frequency used by online travelers to look for travel information must be selected.

Tourism is a very comprehensive industry with broad coverage. Considering the language difference in China and abroad and the vagueness of tourism terminologies, this study takes the six basic travel elements as its foundation. The elements are food, residence, transportation, sightseeing, shopping and entertainment. Combined them with the ranking list of heated search keywords, 9 words are chosen as the keywords of search for travel information in Chinese, which are "accommodation”, "view spots”, "festival”, "vacation”, "gourmet”, "shopping”, "self-service travel”, "tour route” as well as "travel agency".

Among the keywords, "vacation” and "self-service travel” are general keywords. They cover a very broad range of concepts. They are chosen to simulate online users' search with few purposes. And this kind of search normally requires a large amount of information. For instance, one can search for a vacation plan or a route for self-service travel with very few specific requirements. On the other hand, keywords such as "accommodation”, "view spots”, “festival”, "gourmet”, “shopping”, “tour route” and "travel agency” are frequently used when online users are trying to look for information regarding very specific needs.

It needs to be pointed out that it is not reliable only to select keywords that are very general such as tourism. The precision ratio of simulating online users' travel information search behaviors is related to the segment of category. The more specific the keywords are, the higher precision ratio becomes. However, the keywords chosen should not be too limited in concept as well. Because keywords are merely a link to the information search, not its target. Because of the vagueness and uncertainty of the Chinese language, during the search for travel information, categories are restricted. It is understandable and acceptable that the keywords chosen could not cover all aspects of this subject.

\subsection{Choosing Travel Destinations}

In order to make this study more targeted, several travel destination cities are chosen as representatives. Geographic range is applied to narrow down the search. The author took reference from Xiang \& Gretzel (2010) study. In their research, 9 different types of travel destination cities were chosen, which were New York, Chicago, Las Vegas, Dallas, Charlotte and so on. They selected 10 travel keywords, which were "accommodation”, “hotel”, “activities”, “attractions”, “park”, “events”, “tourism”, “restaurant”, “shopping”, and “nightlife”, and assembled them into 90 search combinations to enhance the pertinence of the study. According to the ranking list of the most heated travel destination cities in China, the author takes into consideration of the Guinness ranking list for travel destination cities, the development of tourism in the city, the richness of tourism resources as well as the travel environment evaluation of the city and chooses ten travel destination cities in China as typical keywords for travel destinations. The ten cities are Beijing, Sanya, Guiin, Xi'an, Hangzhou, Lasa, Dalian, Lijiang, Chengdu and Kunming. These cities cover most travelers’ ideal travel destination cities. 


\section{Data Analysis and Discussions}

\subsection{Valid Data Acquisition}

Following Chapter 3, the author assembles the 9 travel information keywords with the 10 travel destination cities into 90 search combinations and use Baidu as the search engine to generate results (samples were taken on 2012-03-15). According to study by Spink \& Japsen (2004), most online users only check the top three pages of their search results. In order to explore the role played by social media in travel information search from a wider perspective, this study adopts data from the top 10 pages of the search results and retrieves a total sample of 9345 (see Table 1 \& Table 2). By eliminating results that are not relevant to travel, 8482 valid samples are acquired, which makes the effective ratio reach $91 \%$.

The display of data can be seen as the following: 1) Analysis of valid data of travel destination cities. Online users look for travel information with 9 keywords through Baidu. Valid websites takes up to over 85\%, with average effective ratio over $90 \%$ (see Table 1). This indicates that by using Baidu as the search engine to look for travel information, data retrieved is faiely effective. It also shows that the keywords chosen for this study match online users' needs to search for travel information. Besides, when online users search travel information about "Sanya", "Lijiang" and "Guilin", the effective ratio can be as high as 96.3\%, 94.7\% and 93.8\%, which suggests that these three words are highly tourismprone. Therefore, little non-tourism information shows up during the search. While the effective ratio for "Beijing" is only $86.6 \%$, illustrating that Beijing is a multifaceted city with tourism only acts as one side of it.

2) Analysis on valid data of keywords for travel search. When online users search for specific travel information about the 10 travel destinations, except for "shopping" (86.0\%) and "festival” (56.6\%), the valid websites

Table 1. Destination search results retrieved from Baidu.

\begin{tabular}{cccc}
\hline Destination & Search Results & Valid Data & Effective Ratio (\%) \\
\hline Beijing & 939 & 813 & 86.6 \\
Sanya & 935 & 900 & 96.3 \\
Chengdu & 939 & 804 & 85.6 \\
Xi'an & 930 & 823 & 88.5 \\
Lasa & 923 & 840 & 91.0 \\
Guilin & 938 & 880 & 93.8 \\
Dalian & 922 & 827 & 89.7 \\
Kunming & 939 & 833 & 88.7 \\
Lijiang & 940 & 890 & 94.7 \\
Hangzhou & 935 & 874 & 93.5 \\
Total & 9345 & 8482 & 90.8 \\
\hline
\end{tabular}

Table 2. Keywords search results retrieved from Baidu.

\begin{tabular}{cccc}
\hline Keywords & Search Results & Valid Data & Effective Ratio (\%) \\
\hline Accommodations & 1078 & 979 & 90.8 \\
View spots & 1027 & 1020 & 99.3 \\
Travel agencies & 1070 & 1054 & 98.5 \\
Shopping & 1014 & 872 & 86.0 \\
Gourmet & 1022 & 977 & 95.6 \\
Vacation & 1029 & 940 & 91.4 \\
Tour route & 1054 & 1052 & 99.8 \\
Self-service travel & 1047 & 1028 & 98.2 \\
Festival & 1004 & 568 & 56.6 \\
Total & 9345 & 8482 & 90.8 \\
\hline
\end{tabular}


retrieved reaches over 90\%, with an average effective ratio of 95\% (see Table 2), which suggests that the keywords chosen for this study match online users' needs to search for travel information and that the information retrieval in Chinese has a high precision rate. Besides, “shopping” (86.0\%) is not confined to shopping during travel, which indicates that search engines tend to use the most common meaning of a keyword to look for relevant information, making the meaning of the keyword pretty general. The effectiveness ratio of the keyword "festival” (56.6\%) is relatively low due to two reasons. For one thing, the events during festivals in China's travel destination cities are normally small in scale with low brand image and little customer coverage. The events are held only occasionally. For another thing, the keyword "festival" is less tourism prone and is therefore not adopted by tourism related company's marketing investment. That is the reason why so many irrelevant websites show up during the travel information search with the keyword "festival".

\subsection{Valid Data Encoding}

This article will now get 8482 valid samples are classified as social media and nonsocial media sites, and further social media sites divided into different types, building to analyze the contents of the category. By reading the literature, reference Wikipedia, Wikipedia classification of the site, you can all travel related websites can be divided into 19 categories. Due to more abundant forms of social media, combined with (social business intelligence company seeisee.com, abbreviated CIC) released revised according to Chinese industry social media landscape overview diagram, above 19 kinds of categories are grouped into types of social media sites. However, CIC released Chinese social media landscape overview diagram type of site is covered by the generalization for more reflect the social nature of social media, two-way, sharing features, the Chinese social media sites into "Wikipedia, Q \& A, document sharing, music/picture/video sharing, consumer reviews, forum/forum aggregation, blog, light blog, microblogging, social content aggregation, social networking sites, business networking, classified information, sign/locationbased services, social games, other” and other 16 categories (CIC, 2012).

\subsection{Reliability Analysis on Data Encoding}

1) Intercoder reliability measurements. To ensure the validity of the content analysis, the authors used testretest method, training coders another pilot study, take the same data collection methods and sample code classification framework, at different times (2012-5-15) conducted a second data collection. Total sample of the study are 9350, among which 8490 are valid. In the content analysis method, depends largely on the level of reliability coder reliability (intercoder reliability). Authors used the Alpha reliability coefficient measurement validity calculated Krippendorff's Alpha 0.89, which indicates the reliability sample code, can be accepted. Although the two measurements separated by a month, the search technology, website development and stability of user habits, the second with the first volume of the collected sample is insignificant with higher effectiveness. Therefore, this study adopts data for analysis.

2) Classification and coding interrater reliability measurements. To ensure the validity of the same classification, the second sample of data collected for further encoding the same, and the Alpha reliability coefficient measurement validity Krippendorff's Alpha value calculated 0.78, although this value is less than the first coefficient, but considering the classification of more, and website construction are moving in a wide and comprehensive trend, so there will inevitably be both can classify the situation.

But the second classification is also the first data encoding correct results. Object of study is the result of online travel information, as the bearer of social media and rapid development of its manifestations web2.0 technology are inseparable, but also has a dynamic nature. Many online travel agents also installed a social media plugins, open up a social media application platform, but according to the nature and function of the main site, they could not be classified as social media sites.

Taking into account the development of the domestic social media will be different and foreign, to ensure that the sample data collected certainty, social media sites should be as concrete manifestations of the breakdown of clear and therefore the first encoding the data included in the 16 classes. Through two samples of data collection for effective coding classification shows, in line with light blog, social content aggregation, business networking, social games and other subdivisions domain results are less effective with thousands of samples compared to the number and does not reflect how much information through communication with the second coder, adjust the classification of social media sites.

Social media networking applications based on the pattern, combined with the nature and substance of the 
website functionality, this article will work with tourist information about the social media sites are divided into Q share classes (social content aggregation, Wikipedia, document sharing, music/pictures/video sharing, etc.), consumer reviews, forum/aggregation, blog, social networking sites (business networking, social gaming, microblogging, light blog, etc.), sign/location services, others (such as classified information) and other eight categories.

\subsection{Analysis on Social Media Data}

Excluding nonsocial media sites can be effective sample (total $=8482)$ in line with the social media site category is further subdivided into eight categories, a total of 2028 reached social media data (specific classification values in Figure 1).

Figure 1 shows, social networking sites, forums/forum aggregation, sharing and quiz classification proportion of the total $85 \%$, indicating that the domestic tourist information website, social media, mainly in the form of these four types. Which functions as a core network social networking sites, classified information, consumer reviews, and relatively independent and high maturity, as a basis function network quiz, document sharing, blog, Wikipedia and other Internet users for other platforms or to provide basic life support functions, and the mode is extremely mature. Microblogging and sign/location based services are emerging network applications, although it accounted for less weight, and its development was faster.

1) The percentage of social media websites take in search for travel destinations' information (see Figure 2).

As can be seen in Figure 2, online users use Baidu Web search ten tourist destination city information, social

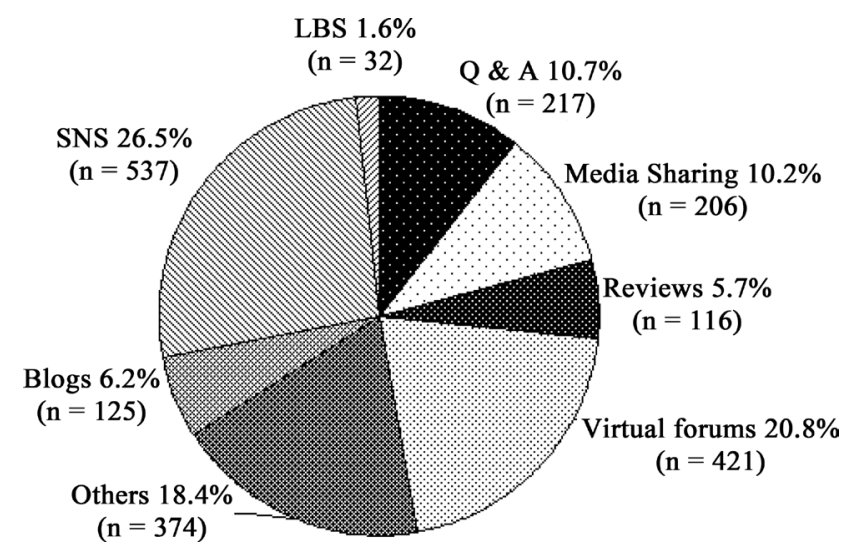

Figure 1. Composition of social media represented in Baidu.

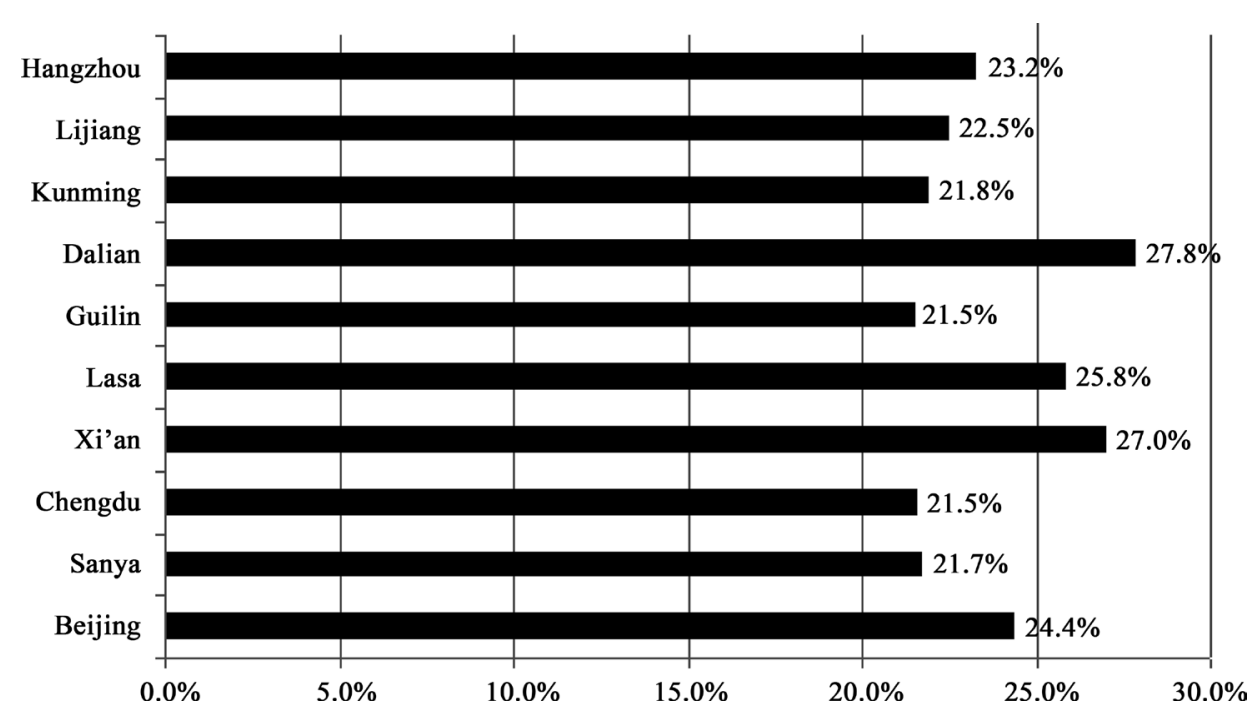

Figure 2. The percentage of social media websites take in search for travel destinations' information. 
media sites the proportion of more than 20, indicating that social media sites as the search for sources of information, is gradually changing tourism service providers the leading provider of information dissemination position. Including Dalian, Xi'an, Lhasa and other cities in the proportion of more than 25\%, indicating that compared to other cities, users of those destinations collective content production, interactive, and more tourist information sharing.

2) The percentage of social media websites in searching for specific travel information (Figure 3).

As can be seen in Figure 3, the user uses Baidu Web search 10 city specific travel destination information, social media sites a higher proportion keywords for "festival”, "shopping”, "gourmet" "Walks" and so on, indicating that users are more inclined to evaluate (merchants), AC(experience), share (shopping food guide) include this information in three areas. At the same time it can be seen, "travel”, "tourist route”, "attraction” and the search results social media sites the proportion of low, indicating that tourism service providers put more of these three keywords, Business Marketing information dominates. In addition, it is worth mentioning that the "festival" in the highest proportion of 53.5\%, indicating that tourists prefer to exchange and share experiences FSE experience, but also further validates network marketing small tourism enterprises put this keyword, so get with tourism festival activities related to social media sites more.

3) Distribution of social media across the top 10 search pages (see Figure 4).

See from the above, a total of 8482 valid samples in 2028 social media sites, and the first 10 search results, social media sites on each page in the proportion of more than $20 \%$ (see Figure 4), indicating that each page 10 presented to the user's search results, at least two website links directing users to be media sites. In addition, the figure shows that social media page results in more uniform distribution ratio, indicating that the search travel information, online users are directed to social media sites such as possibilities.

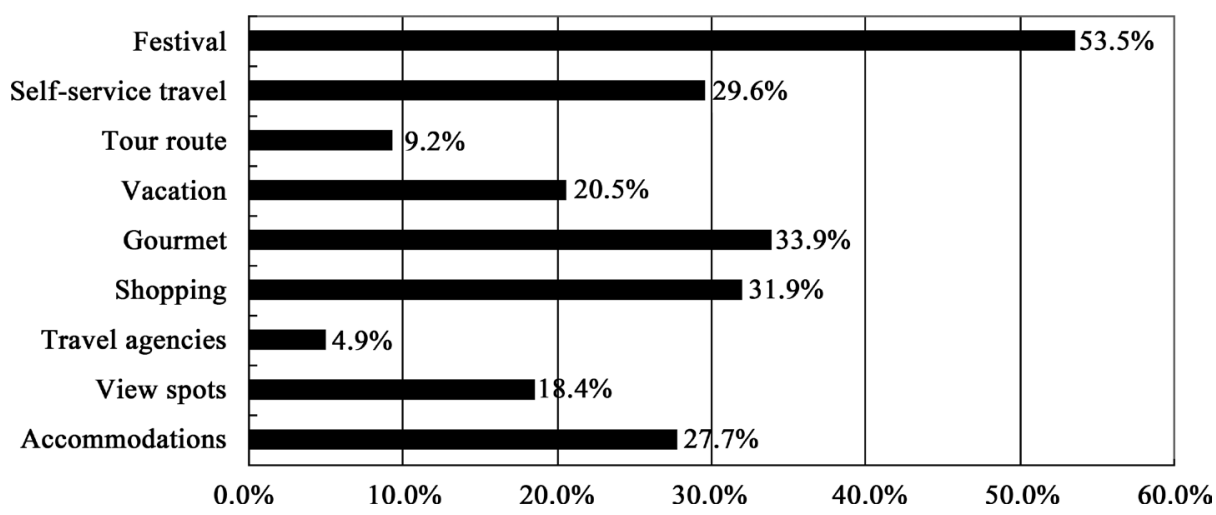

Figure 3. The percentage of social media websites in searching for specific travel information.

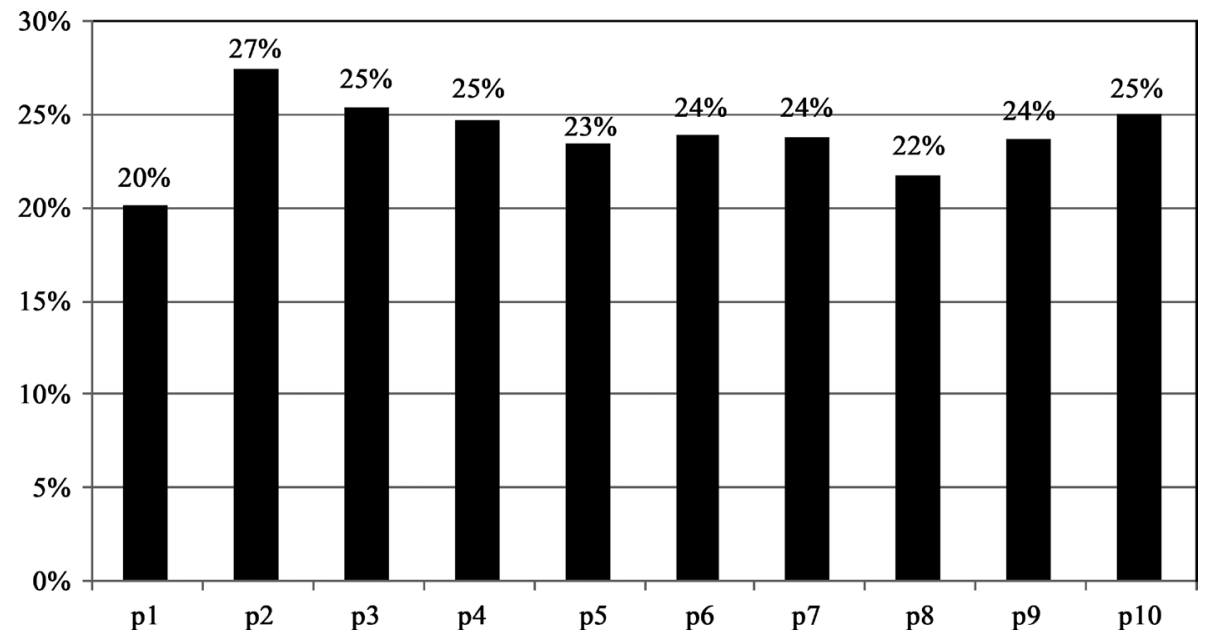

Figure 4. Distribution of social media across the top 10 search pages. 


\section{Descriptive Statistical Analysis}

\subsection{Frequency Analysis on Valid Data}

This article using the SPSS statistical analysis valid sample $(N=8482)$ conducted a frequency analysis, the 3141 does not repeat domain names, of which the first 73 sites cumulative percentage of $40 \%$, compared to a large sample of data concerned, reflects a certain degree of concentration of travel sites. And after a long and cumulative percentage elongation curve gently, indicating effective sample $(N=8482)$ site concentration, the lower travel sites showing a significant distribution of "The Long Tail (Long Tail)" feature, is all small nonoccurrence frequency mainstream travel sites add up, the proportion is much larger than the mainstream tourist sites in the proportion of valid samples.

Search results appear "Long Tail Effect" partly due to the development of Internet technology also shows that, for many small scale tourism enterprises such as local B \& Bs, restaurants, travel agents and flavor provides a fast and low cost information transmission, can be self website information directly accept advice and booking service. It also shows the popularity of Web2.0 applications, the rapid development of social media to promote the explosive growth of content and relationships, so many users themselves into the production platform, so there are more original, but some of the more niche information content distribution sites. Reflected in the flow of information on the Internet, is that the mass tourist information website information on all high end, while the more niche tourism business website or user generated information is located at the bottom of all the information.

\subsection{Frequency Analysis on Social Media Data}

Statistical analysis using the same method, the number of samples social media sites $(N=2028)$ conducted a frequency analysis, the 391 does not repeat the social media domain name. Not repeated in the 391 domain names, the first 23 sites cumulative percentage of $60 \%$, compared to a large sample of data concerned, reflects the strong social media sites concentration. Before the cumulative percentage of 75 websites big $80 \%$, after 316 site appears in the frequency of four times or less, the cumulative percentage of extending long and gentle curves, indicating that social media sample $(N=2028)$ website showing a significant distribution the long-tailed, and also shows the social media, because the rapid growth of user generated content information, coupled with the media tend to become more likely in the medium some kind of information one can easily stop the spread, generate content shunt.

This also explains the Chinese Internet users are more social media identity. According to the latest CNNIC statistics, as of the end of 2010, Internet users reached 457 million, of which social networking site users reached 235 million, blog users reached 294 million, the forum users reached 148 million, online video users reached 284 million. In China, the average Internet users have three social media identity (CNNIC, 2012).

From Xiang \& Gretzel (2010) research results, they chose the first 68 (18\%) 70\% of sites are social media sites, showing significant long-tailed. The author's Chinese study also showed similar characteristics, which shows China's social media development and the application of foreign pattern acquaintance. Global top 20 social networking sites Facebook and MySpace only two, while the domestic top 20 are five: QQ space, everyone, happy, Tencent friends, Baidu space. The following will appear higher frequency of social media sites were analyzed (Table 3); the authors cited a frequency of only the top 30 sites.

Seen in Table 3, the topranking social networking sites, in addition to Baidu Space (hi.baidu.com), Sina blog (blog.sina.com), Watercress (douban.com), Microblogging (weibo.com), Sohu (sohu.com), Tencent Space (qzone.qq.com), Renren (renren.com), Happy Network (kaixin001.com), Netease (163.com) and other mass outside the community, as well as specialized travel community Ant Cellular (mafengwo.cn), Brigade Rating (lvping.com), Mill (doyouhike.net), Travel Living Communities (hicafe.cn), Fish Tourism (yoyv.com) and so on. Most of these social networking sites are equipped with user created travel blog space or homes, save photos, published travels, share travel guides, meet friends, discuss and share travel experiences and other functions.

Ranked by the forum there before World Forum (tianya.cn), Xicihutong (xici.net), Mop Forum (mop.com) earlier in China and other emerging social media, but also further validates the Chinese online forums show the three pillars situation.

Consumer review sites to daodao.com win, it is the world's largest travel site Trip Advisor China's Official Website, is not a travel agency, nor is travel booking service agents, to provide true real traveler reviews, to help 
Table 3. Top 30 unique domain names among social media search results.

\begin{tabular}{|c|c|c|c|c|}
\hline Sequence & Domain & Frequency & Valid Percentage & Cumulative Percentage \\
\hline 1 & Baidu & 342 & 17.4 & 17.38 \\
\hline 2 & Sina & 114 & 5.8 & 23.17 \\
\hline 3 & 58 & 65 & 3.3 & 26.47 \\
\hline 4 & Qu114 & 59 & 3.0 & 29.47 \\
\hline 5 & Mafengwo & 56 & 2.8 & 32.32 \\
\hline 6 & Soso & 52 & 2.6 & 34.96 \\
\hline 7 & Daodao & 51 & 2.6 & 37.55 \\
\hline 8 & Douban & 44 & 2.2 & 39.79 \\
\hline 9 & Ganji & 42 & 2.1 & 41.92 \\
\hline 10 & Lvping & 40 & 2.0 & 43.95 \\
\hline 11 & Tianya & 40 & 2.0 & 45.99 \\
\hline 12 & Dianping & 39 & 2.0 & 47.97 \\
\hline 13 & Becod & 34 & 1.7 & 49.70 \\
\hline 14 & Liebiao & 34 & 1.7 & 51.42 \\
\hline 15 & Edeng & 27 & 1.4 & 52.79 \\
\hline 16 & City8 & 25 & 1.3 & 54.07 \\
\hline 17 & Weibo & 21 & 1.1 & 55.13 \\
\hline 18 & Sohu & 20 & 1.0 & 56.15 \\
\hline 19 & Doyouhike & 19 & 1.0 & 57.11 \\
\hline 20 & QQ & 19 & 1.0 & 58.08 \\
\hline 21 & Renren & 19 & 1.0 & 59.04 \\
\hline 22 & Xici & 18 & 0.9 & 59.96 \\
\hline 23 & Youku & 18 & 0.9 & 60.87 \\
\hline 24 & Kaixin001 & 16 & 0.8 & 61.69 \\
\hline 25 & Hicafe & 14 & 0.7 & 62.40 \\
\hline 26 & Рoco & 14 & 0.7 & 63.11 \\
\hline 27 & Мop & 13 & 0.7 & 63.77 \\
\hline 28 & Tudou & 13 & 0.7 & 64.43 \\
\hline 29 & Yoyv & 13 & 0.7 & 65.09 \\
\hline 30 & 163 & 11 & 0.6 & 65.65 \\
\hline
\end{tabular}

travelers plan a full travel program and provide booking link. Second is the rapid development of the public comment network (dianping.com), an independent thirdparty consumer review site, is committed to providing users of dining, shopping, entertainment and living areas such as business information services, consumer promotions and publishing consumer evaluation of an interactive platform.

Sharing websites, the videosharing Youku (youku.com), Potatoes (tudou.com) based, upload and share content on specific topic communities, are the highest user penetration video sharing site; pictures to share with POCO photo sharing communities (poco.cn) champion, which is based on the core of the original picture sharing community. Interactive quiz class website to Baidu know (zhidao.baidu.com), Soso ask (soso.com) and other community based interactive quiz.

\section{Correspondence Analysis}

Search keyword correspondence analysis to explore the relationship between the tourism destinations. It is widely used in the qualitative data (Category Data) analysis, the aim is to compare the relationship between the variables directly reflects the two dimensional graph in order to achieve two effects: on the one hand, in the 
same category of the dimension between the different variables associated with, so you can have a better understanding of the row and column variables reflecting the relationship between; the other hand, is closer to a dimension on the same distinction between different categories of variables is small, can be identified by the variable classification is reasonable. This text using MINITAB statistical analysis "simple correspondence analysis" can be drawn from the contingency table analysis and the corresponding analysis chart (see Figure 5).

Results from contingency tables analysis show that the first dimension (shaft 1) the proportion of the total inertia of the proportion of $63.4 \%$, the second dimension (axis 2) the proportion of the total inertia of the proportion of $19.7 \%$, both of which $83.1 \%$ percent cumulative, the former two dimensions explanation has more than $80 \%$ can achieve a good effect of the original information. In addition, actually corresponds multidimensional data analysis is to be reduced to a two dimensional space for analysis, retaining only the main information processing, the smaller the weight loss of some information. Therefore, the histogram can also be seen from the first two dimensions explain much higher than several other dimensions, two dimensional graphics can better explain the information between two variables, the importance of other dimensions can be ignored.

Correspondence analysis in Figure 5, if the two components of the distance between the points closer, it indicates that it more closely related.

The figure shows that in the first quadrant of the "consumer reviews" and "tourist routes, shopping, dining", and other words are close, which indicates that users tend to review travel routes, food and shopping and other aspects, social media IF ranked higher degree of public comment (dianping.com), Trip Advisor (daodao.com) verified this link. Public comment network (dianping.com) to provide true gourmet restaurants, shopping, entertainment reviews mainly Trip Advisor (daodao.com) provides real travelers on tours comment.

Also in the first quadrant of the "sign/location services" and "vacation" closer, he explains the user more like to use LBS(Location Based Service) service will sign the line linking the resort activities, while also illustrates the need to get the user to resort information, the more inclined to search for geographical information simultaneously. If samples will effectively meet the "sign/location services", the search results separate frequency analysis, you will find "Baidu side" (shenbian.baidu.com) in the forefront, it is the biggest highlight of any offer two search boxes switch, the user can choose to go first service, look at the location; latter is first locked region, and then screening services. And that "Baidu side" offers a wide range of information search and sharing platform, with a wider coverage of the "holiday" coincide. Of particular note "travel" and the social media categorical variables are far way off, indicating that the use of this keyword search oriented social media sites and there

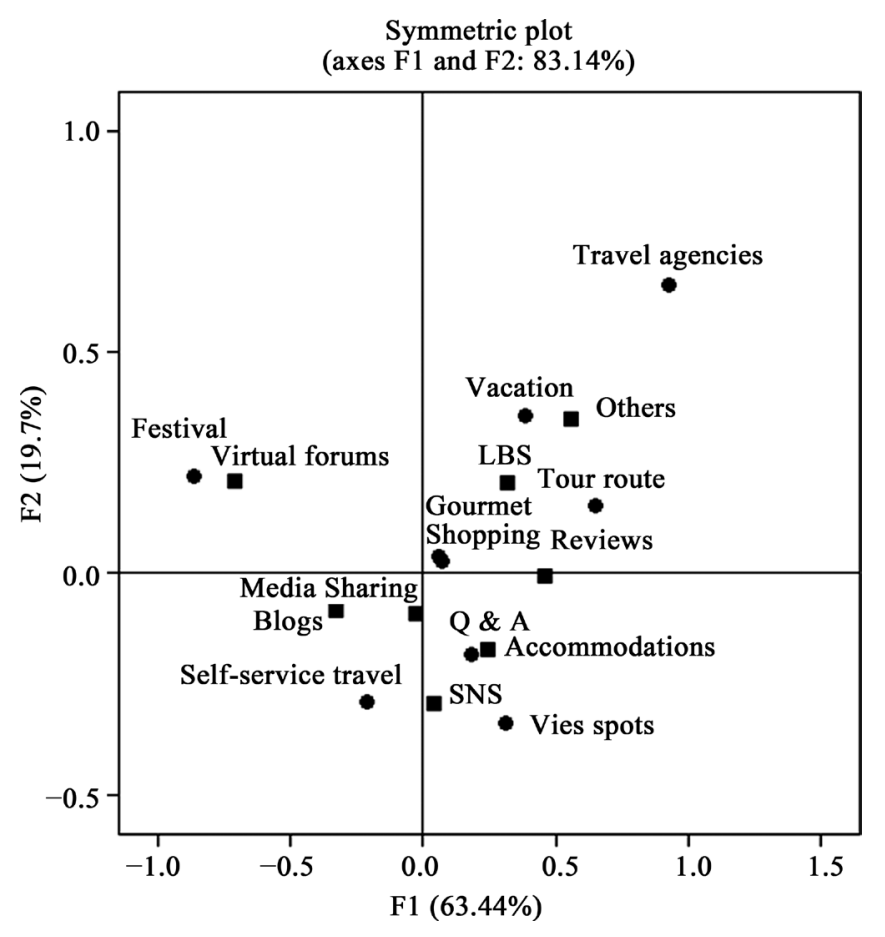

Figure 5. Correspondence between keywords and types of social media. 
are no clear direction and type of sexual preference, there are other classifications shunt out information explaining the possibility of proportion. In Figure 3, "travel” on social media sites the proportion is low, also proved this point.

In the second quadrant of the "forum" and "festival” relatively close, indicating the degree of association between the two larger, with a clear preference for directivity. Tourists prefer the BBS around specific topics and surfers sharing activities of the festival experience. In Figure 3, "festival” in the social media sites the proportion is higher, also confirmed this point.

In the third quadrant of the "blog, share" and "Walks" relatively close, which means that the degree of association of these three large, that "blog" is a traveler sharing or online user experience for many aspects Walks common medium of information. Because the use of personal blog can freely manage, occasional posting new articles, combines text, images, links to other blog or website, etc. related to the topic of the media, and readers can leave comments in an interactive format, compared to other media can be more showing good run in all aspects of the full meaning of the expression, is a private and public nature of the effective combination.

In the fourth quadrant of the "Q" and "accommodation” very close, which means that the larger correlation between the two, with a clear point, indicating the destination Accommodation asking more search results. Meanwhile, "Q \& A, social networking site” and "attraction” is also relatively close, indicating that the information asked destination attractions search results more social networking sites, you can create a personal home page, will be interested in the same tour to travelers, locals and people within social networks together, exchange information on the destination's attractions, such as the main share travel Raiders. In addition, the "social networking site" phase difference is not all the same distance from the two points, "stay" and "Walks”, also shows that social networking sites versatility.

With foreign Xiang \& Gretzel (2010), who compared the findings look abroad "Consumer Review" and "shopping, restaurant" showed a strong correlation; while the "virtual community" is mostly share exchanges. "Tourism, events, accommodation, attraction" core information and other tourist activities, which is the main forum for discussion with the domestic activities of different festivals, Chinese domestic" social networking sites, images/video sharing, blog “and” nightlife, festivals, Park "has a strong correlation between the polymerization.

\section{Conclusion}

First of all, from data analysis in the previous chapter, it is clear that social media provides a variety of sources to travel information search. Although social media information only covers around $24 \%$ of all search results and merely a certain proportion of social media websites show up among the search results according to the distribution of keywords and the search results, the actual proportion of social media information on the Internet that is not represented in the ranking list of search results is far more lager. The author did not choose to use professional vertical travel information search engines to make sure that the data and conclusion of this study stay convincing and objective. If the data are adopted from other sources such as qunar.com or auyou.cn, the travel information will be too commercialized, turning the focus of this study to travel company's travel information search. And comparison study cannot be made under such circumstance. Using Baidu as the search engine fits the search preference of online users and makes the data from this simulating study more convincing. The data of this study comes from a variety of sources, including the three sources of travel information stated above, which emphasizes the importance of social media. There is a point to be made here which is that most social media information tends to be UGC and processes the characteristics of a third party, making it lacks marketing competitive edge for travel companies. Travel companies can purchase keyword search for various websites which can later be used for Baidu's biding listing. In this way, theses websites are more likely to appear as reach results by search engines than social media websites, and can attract more attention from online users. It can be concluded from all of above that social media generates great amount of travel information despite of the fact that data in this study can only be able to represent a very little part of all social media data. The development of social media in the future will generate more information than travel destinations and travel companies’ marketing departments.

Secondly, social media boosts the reconstruction of travel information. It can be drawn from this study that travel information generated from social media is abundant. Profound transformation of information sources' social structure is under way. The dominant position of official information sources and travel companies' in- 
formation are going to change. This can be seen from the following signs: 1) The number of domestic social media users in China is rapidly expanding. Latest statistic data published by CNNIC in 2010 suggests that by the end of 2009, the total number of China's social media users had reached over 124 million, among which over a quarter spent an average of 1 to 2 hours per day on social media platforms (CNNIC, 2011b). 2) Social media is frequently used in China. Global Web Index, which was an Internet research institution abroad, conducted a research on global Internet users in 2010. The result turned out that the percentage of social media used in China reached $70 \%$ in 2009. Social media has already penetrated into online users' daily life. 3) Websites with the feature of social media is emerging quickly and more contents are posted by users appear. According to The Report on Development of China's Social Media in 2009 published by Daqi, information originated by users such as messages, videos and blogs has reached 1.13 billion, among which 370 million are commercial related. Travel information generated by social media on the Internet is extremely abundant. Online users no longer rely on travel companies or local government of travel destinations to gain travel information (Daqi, 2010).

Thirdly, social media changes the distribution of travel information. Social media is playing a more and more important role in the area of online tourism. The distribution of travel information would rely more on the platform of social media, which changes the traditional way of the distribution of travel information. The most distinguished difference between social media and traditional media is that social media provides a way of participation for online users. Online users no longer receive information from travel operators passively through social media. They can generate and distribute firsthand information and communicate with whoever receives the information. Therefore, the emergence of social media changes the way that traditional travel information is posted. The traditional distribution pattern is one-way while the new pattern is two-way.

Last but not least, social media recreates the searching process of travel information. Search engine is the bridge between online travelers and travel service providers. Online travelers look for information through search engines while travel service providers and operators present their website information on search engines through a commercial approach known as "keywords bidding listing" to attract online travelers to click in their websites. China's travel information search market has been expanding with an amazing speed recently. Besides professional vertical travel websites such as qunar.com, kuxun.cn as well as linxun.com, travel.sina.com, trip.taobao.com and lvyou.baidu.com also provide a platform for information search on tourism merchandises with the assistance of search keywords. Because of the one-way distribution and overmarketing of commercial information, online travelers lack confidence in the information posted by travel service suppliers. And hence, noncommercial travel information such as personal experience becomes the No.1 choice for online travelers while searching for travel information.

\section{Implications}

Travel service providers such as scenic spots, hotels and travel agencies either rely on large online tourism trading platform or create their own tourism marketing platform in order to post information covering "clothing, accommodation, transportation, traveling, shopping and entertainment". Online travelers merely receive the information through this one-way channel passively. However, the emergence of social media makes it possible for online travelers to create and post UGC related to tourism through the platform of social media and also communicate with any potential traveler, which changes the dominant position of travel service providers in the distribution of travel information. With the mounting amount of UGC travel information, travel companies will go for social media marketing initiatively.

The way of optimizing traditional search engines could no longer fulfill the need for flow from travel service providers. This obvious change pushes search engines to solve problems such as low coverage of search results, low efficiency of search results and the impartiality of search results during data collection. More importance should be attached to collecting texts, images, videos, travel notes, comments as well as UGC information concerning travel destinations' scenic spots, accommodations and transportation from various third party social media platforms. Therefore, besides getting commercial information from business, travel information search should apply social media information search technics such as gathering, sharing and DIG systems so as to acquire UGC travel information from social media like travel forums, blogs, SNS(Social Network Site), Weibo and Space. Search results presented to potential online travelers should be composed of both commercial information as well as UGC information.

As a newly emerged area for research, social media is closely related to online tourism and processes an 
enormous room for potential researches. Further studies can be conducted using multiple search engines and then make comparison between comprehensive search engines and professional vertical search engines. Or comparisons can be made among multiple search engines of the same kind. For future researches, exploration on online travel information search could do deeper. For instance, studies could be carried out on the influencing factors of online information search or the influence of social media on the decisionmaking of online travel consumption, etc. More efforts should be devoted into further excavation on this subject matter.

\section{Acknowledgements}

This study was sponsored by both "Guangdong Science and Technology Project” (Grant Number: 2012B031400 008) and "2012 Guangdong Higher Education Reform Project” (Grant Number: 2012069).

\section{References}

Bei, L. T., Chen, E. Y. I., \& Widdows, R. (2004). Consumers' Online Information Search Behavior and the Phenomenon of Search vs. Experience Products. Journal of Family and Economic Issues, 25, 449-467.

http://dx.doi.org/10.1007/s10834-004-5490-0

Bertolucci, J. (2007). Search Engine Shootout. PC World, 25, 86-96.

Bettman, J. R. (1979). Information Processing Theory of Consumer Choice. Boston, MA: Addison Wesley.

Bhatnagar, A., \& Ghose, S. (2004). Online Information Search Termination Patterns across Product Categories and Consumer Demographics. Journal of Retailing, 80, 221-228. http://dx.doi.org/10.1016/j.jretai.2003.10.001

Chu, R. (2001). What Online Hong Kong Travelers Look for on Airline Travel Websites. International Journal of Hospitality Agement, 20, 95-100. http://dx.doi.org/10.1016/S0278-4319(00)00046-3

CIC (2012). From Social Media to Social Commercialism. http://www.ciccorporate.com/index.php?option=com content\&view=category\&id=173Aiwomwatch\&layout=blog\&Itemi d=5\&lang=zh

CNNIC (2011a). Research Report on China's Search Engine Market in 2011. http://news.xinhuanet.com/tech/2011-12/21/c_122458819.htm

CNNIC (2011b). The 28th Statistical Report on the Development of Internet in China. http://www.cnnic.cn/research/bgxz/tjbg/201107/t20110719_22120.html

CNNIC (2012). The 29th Statistical Report on the Development of Internet in China. http://www.cnnic.cn/research/bgxz/tjbg/201201/t20120116_23668.html

Daqi (2010). The Development Report of China’s Social Media in 2009. http://koubei.daqi.com/article/2921217.html

Dogan, G., \& Ken, W. (2004). An Integrative Model of Tourist Information Search Behavior. Annals of Tourism Research, 31, 353-373. http://dx.doi.org/10.1016/j.annals.2003.12.004

Gretzel, U. (2006). Consumer Generated Content Trends and Implications for Branding. Review of Tourism Research, 4, 9-11.

Hyde, K. F. (2008). Information Processing and Touring Planning Theory. Annals of Tourism Research, 35, 712-731. http://dx.doi.org/10.1016/j.annals.2008.05.001

Jun, S. H., Vogt, C. A., \& MacKay, K. J. (2007). Relationships between Travel Information of Travel Research, Search and Travel Product Purchase in Pretrip Contexts. Journal of Travel Research, 45, 266-274. http://dx.doi.org/10.1177/0047287506295945

Pan, B., Litvin, S. W., \& O’Donnell, T. E. (2007). Understanding Accommodation Search Query Formulation: The First Step in Putting "Heads in Beds". Journal of Vacation Marketing, 13, 371-381. http://dx.doi.org/10.1177/1356766707081013

Pan, B., MacLaurin, T., \& Crotts, J. C. (2007). Travel Blogs and Their Implications for Destination Marketing. Journal of Travel Research, 46, 35-45. http://dx.doi.org/10.1177/0047287507302378

Pan, B., Smith, W. W., Zhang, L., \& Li, X. (2007). Satisfaction of Online Rip Planning: Amixed Method Approach. 5th BiAnnual Symposium of the International Society of Culture, Tourism and Hospitality Research, Charleston, 4-6 June 2007.

Pudliner, B. A. (2007). Alternative Literature and Tourist Experience: Travel and Tourist Weblogs. Journal of Tourism and Cultural Change, 5, 46-59. http://dx.doi.org/10.2167/jtcc051.0

Senecal, S., \& Nantel, J. (2004). The Influence of Online Product Recommendations on Consumers Online Choices. Journal of Retailing, 80, 159-169. http://dx.doi.org/10.1016/j.jretai.2004.04.001

Sun, C., \& Liu Y. (2008). Online Travelers' Consumption Behaviors and Application of Travel Websites under the Environment of Web2.0. Huadong Economics Management, 22, 122. 
Tussyadiah, I., \& Fesenmaier, D. R. (2009). Mediating Tourist Experiences: Access to Places via Shared Videos. Annals of Tourism Research, 36, 24-40. http://dx.doi.org/10.1016/j.annals.2008.10.001

Xiang, Z, Wöber, K., \& Fesenmaier, D. R. (2008). Representation of the Online Tourism Domain in Search Engines. Journal of Travel Research, 47, 137-150. http://dx.doi.org/10.1177/0047287508321193

Xiang, Z., \& Gretzel, U. (2010). Role of Social Media in Online Travel Information Search. Tourism Management, 31, 179-188. http://dx.doi.org/10.1016/j.tourman.2009.02.016

Yu, H. (2010). A Study about the Influence of Online Travel Information on Travel Decision Making. Master's Thesis, Changsha: Hunan Normal University. 